\title{
Dramatic play as a means to explore and support preschool children's thinking about thermal insulation
}

\author{
Glykeria Fragkiadaki', Anna Armeni², Stella Zioga3, Konstantinos Ravanis ${ }^{4}$
}

\begin{abstract}
Research in young children's ideas, representations, and pre-conceptions about the natural and technical world has a long history. Most of the studies in the field have used individual, semi-structured interviews as a methodological technique to generate and collect empirical data. However, less is known about how tracing procedures can come in line and be incorporated into everyday educational reality in early childhood settings in a way that reflects young children's interests and needs. The present study uses dramatic play to trace young children's thinking in science and advance their science learning experiences. The study focuses on a science concept young child are familiar with in everyday life though has not been thoroughly studied in the literature yet: thermal insulation. Empirical data from 6 pre-schoolers in Greece are presented. Qualitative data were collected through recordings of children's dialogues, children's drawings, field notes from the early childhood teachers, and photographs. The findings revealed that during their dramatic play children a) developed basic argumentation to express their thinking about the phenomenon; b) related the phenomenon with the thermal condition and changes in temperature; c) identified materials and objects with insulating properties and distinguish them from others with non-insulating properties, and d) came to the conclusion that the use of amplified insulation materials can lead to better insulation results. The outcomes of the study add to the research methodology in early childhood science education and inform practice providing a pedagogical framework that balances between play-based pedagogies and advanced learning outcomes in science for young learners.
\end{abstract}

\author{
Article History \\ Received: 11 April 2021 \\ Accepted: 08 July 2021
}

\section{Keywords}

Dramatic play; Ideas;

Representations; Pre-

conceptions; Science concept

formation; Thermal

insulation- melting;

Solidification; Early

childhood

\section{Introduction}

Research in young children's ideas, representations, and pre-conceptions about the natural and technical world has a long history (Ravanis, 2017). Several empirical studies have explored children's scientific thinking about a wide range of science concepts such as optical and sound phenomena (Delserieys et al., 2017; Pantidos et al., 2017; Ravanis et al., 2021; Smith \& Trundle, 2014), the properties of matter phenomena, (Christidou et al., 2009; Kalogiannakis et al., 2018), mechanic and engineering phenomena (Hadzigeorgiou, 2002; Larsson, 2013), phenomena associated with electricity (Calo Mosquera et al., 2021; Kada \& Ravanis, 2016; Rodríguez-Moreno et al., 2020; Solomonidou \& Kakana, 2000), and e) astronomical and meteorological phenomena (Fragkiadaki \& Ravanis, 2015; Malleus et al., 2017; Saçkes et al., 2016; Trundle \& Saçkes, 2010). Most of the studies in the field have used individual, semi-structured interviews as a methodological technique to generate and collect empirical data sets. However, less is known about how tracing and eliciting procedures can be tailored to young children's educational needs and be incorporated into everyday early childhood educational reality in a way that reflects young children's interests.

\footnotetext{
${ }^{1}$ Monash University, Faculty of Education, Frankston, Australia, e-mail: glykeria.fragkiadaki@monash.edu, ORCID: https://orcid.org/0000-0001-7280-783X

2 University of Patras, Department of Educational Science and Early Childhood Education, Patras, Greece, e-mail: armenianna2@gmail.com, ORCID: https://orcid.org/0000-0002$\underline{3031-4401}$

${ }^{3}$ University of Patras, Department of Educational Science and Early Childhood Education, Patras, Greece, e-mail: stella230593@gmail.com, ORCID: https://orcid.org/0000-0002$\underline{8374-5715}$

${ }^{4}$ University of Patras, Department of Educational Science and Early Childhood Education, Patras, Greece, e-mail: ravanis@upatras.gr, ORCID: https://orcid.org/0000-0002-4429$\underline{3381}$
} 
The present empirical study aims to explore how dramatic play (Fleer, 2011, 2013) can be used as a means to trace as well as to support young children's thinking in science. The study focuses on a science concept that children are familiarized with from the very early beginning of their lives but few studies in the field have explored: the concept of thermal insulation. Empirical data from six preschoolers, aged between 5 to 6 years old, in a kindergarten classroom in Greece are presented. As part of the study design, children's dramatic play was inspired by the children's book entitled "A Little Bit of Winter" written by Paul Stewart. Four diverse activity settings were organized by the two early childhood teachers of the classroom in collaboration with the research team to stimulate children's dramatic play about the story concerning the natural phenomenon. Qualitative data were collected through recordings of children's dialogues during dramatic play, children's drawings, field notes from the early childhood teachers, and photographs of children's dramatic play. Indicative case examples are presented. Drawing upon the system of concepts of cultural-historical theory the concept of the interrelation between everyday concepts and scientific concepts was used as the main analytical tool. It is argued that dramatic play can give an insight into the way young children think about thermal insulation and at the same support the formation of the concept through play-based settings.

The paper begins with a literature review of the challenges young children face in approaching thermal phenomena. This is followed by an overview of how dramatic play is conceptualized in the present study as well as the critical role of dramatic play in early childhood science education. The findings documented the way preschoolers conceptualized and approached the natural phenomenon of thermal insulation during their dramatic play. It was shown that through the intuitive dealing with materials and objects children a) developed basic argumentation to express their thinking and developed an explanation about the natural phenomenon, b) identified materials and objects with insulating properties, c) distinguished these materials and objects from others with non-insulating properties, and d) came to the conclusion that the use of amplified insulation materials can lead to better insulation results. What was also shown is that dramatic play allowed children to realize, unpack, share and use their everyday understandings and real-life experiences to start forming the scientific concept of thermal insulation. The study suggests dramatic play as a social and cultural activity for tracing and, at the same time, supporting the development of young children's ideas and thinking in science. The paper concludes with an insight into how the findings advance the research methodology in early childhood science education research. The outcomes of the study also inform practice providing a pedagogical framework that balances between play-based pedagogies and advanced learning outcomes in science for young learners.

\section{Thermal Phenomena in Early Childhood Science Education}

A limited number of empirical studies have shown young children face difficulties in conceptualizing thermal phenomena (Cain \& Lee, 2020; Cruz-Guzmán et al., 2017; Kampeza et al., 2016). Most of these studies have focused on aspects of young children's understandings of simple changes in the state of water.

To categorize the mental representations of children aged between 5 to 11 years old, Russel et al. (1989) introduced and implemented a set of tasks related to the concept of evaporation. The categorization of young children's representations provided a systematic tracing and recording with specific reference to the notions of conservation, change of location, and change of form of the water. In her research about the circle of water in nature, Bar (1989) studied changes in the state of water concerning the retention of the water. It was shown that till the age of 6 to7 years old, children do not yet conceptualize that water or vapor retains while till the age of 8 years old can conceptualize the retention of water but not the retention of the vapors. In line with this research perspective, Bar and Galili (1994) found similar outcomes for early childhood children. Tytler (2000) also studied the development of 6 to 7 years old children's thinking about evaporation and condensation focusing on tracing patterns at their replies. Patterns were based on the description of the phenomena and not on the explanation of them or the interrelation with specific aspects of experimental situations. Another study also explored the mental representations of children aged between 5 to 6 years old about melting and solidification of salt which is mostly found in the state of solid 
in everyday life (Ravanis, 2014). This research has shown that the most critical aspect of children's thinking was the familiar state of salt as solid.

Ravanis and Bagakis (1998) after tracing the obstacles in children's 5 to 6 years old thinking, used a specialized teaching strategy to lead their thinking towards the approach of the stages of evaporation. Cruz-Guzmán et al. (2017) research also focused on the same topic researching with children aged between 2 to 4 years old. This research followed a process of predictions and experimental confirmation about the changes in the state of matter of everyday materials. Finally, Kambouri-Danos et al. (2019) implemented a teaching intervention into phases. During these phases, children between 5 to 6 years old were asked to do predictions and interpretations for several changes in the state of water aiming at recognizing changes in temperature such as cooling and warming as a reason for the changes.

From this limited number of studies, it can be seen that early childhood children approach thermal phenomena in a non-stable and non-general way. Children interrelate the temperature of objects with the size of the objects as well as recognize the thermal properties of the materials the objects are made of. Regarding the changes in the state of matter young children can conceptualize vapor as the outcome of boiling water. However, children at that age do not realize that vapor becomes water again but usually believe that it disappears or enters solid materials. Moreover, the cases that the changes in the state of the matter are conceptualized efficiently by the children are related to these changes that happen as everyday phenomena and do not apply in other materials.

Despite the variety of research studies related to children's largely understanding of the thermal phenomena, less is known about how young children conceptualize thermal insulation. This is particularly surprising given that young children are experiencing thermal insulation daily as an everyday phenomenon in real life. For example, they put on their coat in order not to be cold when they play outdoors, or they use food containers made with thermal insulation materials to keep their lunch warm at school. What is known until now from the empirical literature is that young children tend to conceptualize insulation as a property of the materials (Paik et al., 2007). Touching upon thermal insulation at a theoretical level, Fleer (2008) gives an insightful example to explain how young children think about science concepts. She mentions that children wear sweaters when they are cold, and they know that this will keep them warm. This is an understanding based on children's daily experiences. However, this does not mean that children know the scientific explanation that lays behind it. As a result, children are more unlikely to understand the interrelations in diverse settings such as when they are trying to keep warm in the water by wearing a surfing costume. Further empirical research must be done and deeper knowledge has to be gained in order to understand how young children think about this phenomenon they experience everyday and what scientific explanations do they form to approach the phenomenon. The present study seeks to explore how young children conceptualize and develop their thinking about thermal insulation. How dramatic play can be used as a means to trace as well as to support young children's thinking towards science concepts such as thermal insulation is elaborated in the next subsection.

\section{Dramatic Play as a Pedagogical Practice in Early Childhood Science Education}

The diverse psychological aspects of drama have been explored widely in the literature (Courtney, 1989; Wolf \& Kase-Polisini, 1985; Wright, 1999). These studies have highlighted the critical role of the concept of drama in the process of the development of the personality. Beyond the psychological aspect, drama has a critical role in play-based pedagogical frameworks. Research has shown that drama in early childhood settings is a dynamic pedagogical practice and a valued learning medium that promotes cultural, social, emotional, and intellectual learning and development (Brown, 2017; Courtney, 1989; Gao \& Hall, 2019; Neelands, 2002; Vidal Carulla et al., 2021). Following a Vygotskian (Vygotsky, 1987) and postVygotskian (Elkonin, 1977, 1978; Leont'ev, 1978) perspective, dramatic play is conceptualized here as the leading activity for preschool and kindergarten age children and is distinguished by other activities by indicating that during dramatic play young children take on a role of another entity, for example, they pretend to be another person, an animal, or an object and use objects in a symbolic way, for example, they use a cardboard box as a spacecraft (Bodrova \& Leong, 1998). As Mellou (1994) argues, the value of 
dramatic play for young children lies in five basic functions: "1) it provides personal expression and catharsis of inner desires; 2 ) it helps the child to distinguish between reality and fantasy; 3 ) it provides for children's social adaptation: 4) it is dynamic for learning; and 5) it improves intellectual development and specifically creativity, through interaction, transformation and imagination" (p. 105). Through their dramatic play, young children express themselves in intellectual, affective, and embodiment levels. They learn about their social and cultural reality as well as about the natural, technical, and technological world. They communicate with their peers and the early childhood teachers, they set and accept rules, undertake different roles, and develop their self-regulation. Being in a role through their body positioning, their gesture, their speech, their tone of voice as well as through the mediation of cultural artifacts and the material surroundings, children create new abstract as well as concrete learning spaces. Through dramatic play, children also form their perceptions and interpret everyday life as well as transform and expand their reality through their imagination and creativity.

Despite the wide range of studies related to drama and dramatic play in the early years (Brown, 2017; Dunn, 2003; Furman, 2000) as well as the interrelation between drama and secondary and primary science education (Dorion, 2009; McGregor, 2012; Metcalfe et al., 1984; Ødegaard, 2003; Pantidos et al., 2001; Varelas et al., 2010), less is known about the role of dramatic play in early childhood science education. Limited research has shown that diverse forms of drama can be a key asset in learning and development in science in the early years.

Fleer $(2011,2013)$ has highlighted this dialectic interrelation at a theoretical level and has also introduced a play-based model of practice that combines drama and dramatic play with science, technology, engineering, and mathematics (STEM) concept formation. In her model named Conceptual PlayWorlds model (Fleer, 2018) she suggests using drama and dramatic play to stimulate young children to enter an imaginary situation inspired by a children's book. Being within an imaginary situation along with the early childhood teachers, children are introduced into problematic situations that require the formation of a set of science and/or STEM concepts in order to be solved. Thus, young children begin forming the concepts within the imaginary situation while they are experiencing the drama and as part of their dramatic play (Fleer et al., 2020; Rai et al., 2021).

Fleer (2013) also suggests that using drama as a pedagogical practice can unpack the emotional nature of young children's scientific learning in pre-school and support children's s scientific learning in early years. She argues that through dramatic play inspired by fairy tales young children can develop their scientific consciousness and craft scientific narratives about the concepts and the phenomena of the natural world. What is critical in this direction is that early childhood teachers bring together science and fairy tales into a form of scientific drama that is meaningful for the child and allows the child to explore the surrounding world through play and imagination.

Remountaki et al. (2017) also used dramatic play to explore the ideas of children between 5 to 6 years old for the phenomenon of dissolution of solid substances into liquids. It was found that the use of a puppet, handled by the early childhood teacher, stimulated children to develop their dramatic play and at the same time orient the children towards the formation of the concept of dissolution. As part of their dramatic play, children wonder about the phenomenon, used their everyday knowledge and experience to form a scientific understanding of the phenomenon, and managed to systematically engage with early forms of science methodology such as the development of the trial skill.

Kambouri and Michaelides (2014) have also touched upon the interrelation between drama and early childhood science education. Focusing on the concept of water circulation in nature their research has shown evidence that drama can facilitate children's scientific understanding and also lead to the improvement in the children's use of vocabulary concerning the science concept that is explored. As Kambouri and Michaelides argued (2014) what is critical when using drama techniques for teaching science in early years is to emphasize the development of children's understanding of the science topic under investigation rather than on the correct and efficient implementation of the drama techniques. 
What we have learned from the above studies is that dramatic play has a critical role in supporting young children's engagement, learning, and development in science. However, more has to be learned about how dramatic play can be used to get a better insight into children's thinking in science and to support the formation of science concepts as part of the child's everyday educational reality. Focusing on the underexplored science concept of thermal insulation, the study reported to this paper seeks to address this gap by answering the following research question: How dramatic play creates the conditions for tracing and supporting the process of thermal insulation concept formation in early childhood settings?

\section{Method}

\section{Study Design}

The study design was based on children's dramatic play during everyday educational reality in early childhood settings. Children's dramatic play was inspired by the children's book entitled "A Little Bit of Winter" written by Paul Stewart. The story of the book is about the friendship of a rabbit and a hedgehog. The hedgehog is facing a problematic situation: he has never seen snow since he goes into hibernation each winter. While the hedgehog is sleeping throughout the winter, the rabbit is trying to keep a snowball for him. He decides to cocoon the snowball in a bunch of leaves to prevent snow from melting. When the winter ends and the hedgehog goes out of hibernation, he finds the leftovers of the snowball.

Four diverse activity settings were organized based on the story as part of the research procedure. Each activity setting was held on different days, during the period of two weeks, following the educational routines of the class and lasted approximately twenty-five minutes. During the four activity settings, children were given the time and space to explore their ideas, express their narratives and argumentation and collaborate with their partner in the dramatic story to find a solution to the introduced problem. The activity settings were organized as follows:

First activity setting: Engagement with the story. The first activity setting aimed at stimulating children to wonder and unfold their thinking about insulation. Children were encouraged to craft a narrative around their conceptualization of the phenomenon making interrelations with everyday real-life experiences and understandings about the phenomenon. The early childhood teachers read the story with the children. As a team, the children and the early childhood teachers discussed commented and reflected on the story. In that phase, early childhood teachers supported children to focus their attention on the concept of thermal insulation, melting, and solidification. The concepts were discussed descriptively, without using specific terminology or any other scientific explanation. Storytelling and the following discussions took place in a space of the classroom that the early childhood teachers had transformed to look like the forest that the two of the story animals lived (e.g., a tree, leaves, pieces of ice).

Second activity setting: Experiencing the story through dramatic play. The second activity setting aimed at stimulating children to explore the materials used in the story, that is leaves and ice. Children were encouraged to experience the phenomenon and make predictions, test, describe, and explain the phenomenon as well as craft a narrative around their explorations. Children were engaged in couples in a dramatic play inspired by the story using a set of props such as a tail and a pair of ears pretending to be in the character of the rabbit and the hedgehog. The focus of the dramatic play was to explore ways of preventing a piece of ice from melting. Children were given ice-cubes representing snowballs in their dramatic play. The leading question and problem to be solved by the children were "How can we keep the snowball?". In that activity setting children used the same materials that the rabbit had used in the book, that is leaves. Early childhood teachers supported children's explorations by posing questions and stimulating the children to wonder about the concept of thermal insulation, melting, and solidification (e.g., "Why are you cocooning the ice, rabbi?", "What do you expect happening after cocooning the ice?", "What do you think is going to happen if you do not do cocoon the ice", "How do you know this?").

Third activity setting: Expanding the story through dramatic play. The third activity setting aimed at stimulating children to explore a set of diverse materials in order to make predictions, test, describe and 
explain the phenomenon as well as craft a narrative around their explorations. Children and the early childhood teachers continued the dramatic play inspired by the story. The problematic situation that was introduced in that phase was expressed as follows: "We have now run out of leaves! What should we do to keep the ice as it is?". Children have at their disposal a set of additional materials and objects such as aluminum foil, paper napkins, a plastic bag, a piece of cloth. Children were encouraged to select the material they consider more appropriate for preventing ice melting as well as to express their argumentation (Convertini, 2019) regarding their choice (e.g., "Which material do you think that is more appropriate for keeping the snowball as it is?", "How do you know that?", "What will happen when you cocoon the ice with this material?").

Forth activity setting: Using drawings to overview the overall experience. The fourth activity setting aimed at encouraging children to draw their overall experience and their understandings of the natural phenomenon. Children also explained, commended, and created a narrative around their drawings which they shared with the early childhood teachers and their peers.

The dramatic play was present throughout children's engagement with the science concept during the activity settings. Children had the possibility to lead the dramatic play based on their interests. Early childhood teachers' role was supportive to children's explorations of objects and materials during the dramatic play. Early childhood teachers consistently stimulated children to express verbally their thinking as well as document their thinking around the science concept through drawings.

\section{Participants}

Six preschool children participated in the study. The children were aged between 5 to 6 years old and were attending one kindergarten classroom in an urban area in Greece. The six children participated in the data generation process after expressing their will to join the dramatic play initiated by the early childhood teachers of the classroom. Parents' informed consent was given. The study was approved by the Ethics Committee of the Department of Educational Sciences and Early Childhood Education of the University of Patras. Children had no previous engagement in teaching and learning interventions regarding the concepts of thermal insulation, melting, and solidification. Two early childhood teachers of the classroom also took part in the study. Both teachers had less than two years of teaching experience and had not previously participated in professional development programs for teaching science in early childhood settings.

\section{Data Collection and Analysis}

Qualitative data were collected through a) recordings of children's and early childhood teachers' dialogues during dramatic play (approximately 1 hour and 40 minutes in total); b) their drawings after each activity setting ( 24 drawings in total); c) field notes from the early childhood teachers (4 pages in total); and d) photographs of children's dramatic play (20 photographs in total). Conversational analysis (Pea, 1993; Sacks, 1995) of the transcripted dialogues and narratives were carried out supported by the documentation from the drawings, the field notes, and the photographs. The analysis aimed at capturing critical moments when, using dramatic play, children managed to start developing early forms of the science concept. Themes such as interrelation with the thermal condition and changes in temperature, interrelation with everyday life as well as codes such as mentioning heating sources, mentioning family routines and interactions with adults emerged from the empirical data during the qualitative analysis.

\section{Results}

The overall findings of the study have shown that dramatic play allowed children to a) develop basic argumentation to express their thinking about the phenomenon realizing that several materials and objects can prevent ice melting; $b$ ) relate the phenomenon with the thermal condition and changes in temperature; c) identify materials and objects with insulating properties and distinguish these materials and objects from others with non-insulating properties, and d) come to the conclusion that the use of amplified insulation materials can lead to better insulation results. What was also shown is that dramatic play created the 
conditions for the children to interrelate their everyday knowledge and experience about thermal insulation as an everyday phenomenon with a scientific explanation that is compatible with the explanatory model that can be used in education about the phenomenon. The detailed findings and indicative examples of how children start forming the concept of insulation through dramatic play are presented below.

\section{Developing Basic Argumentation About the Phenomenon as Part of The Dramatic Play}

The findings revealed that children unfold and expressed their ideas about the phenomenon as being in the character of the rabbit or the hedgehog while handling and experimenting with the materials and objects during their dramatic play (Figure 1).

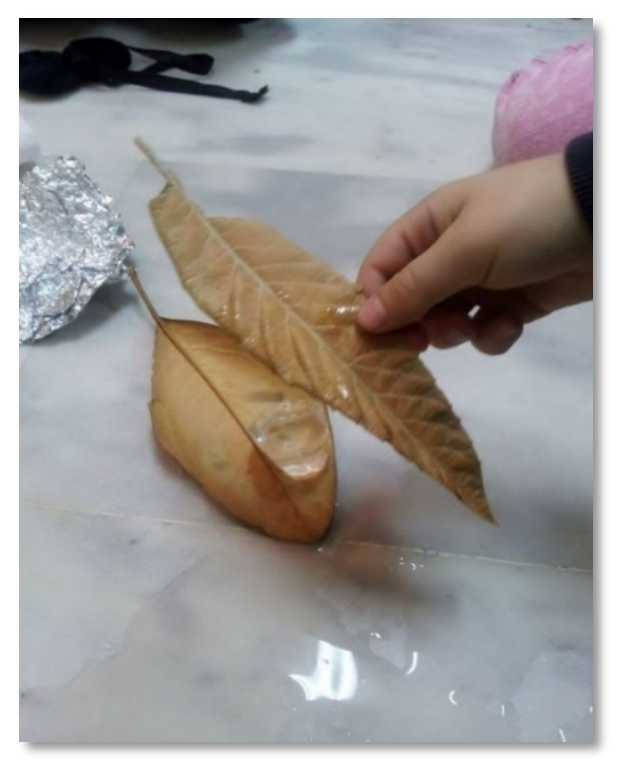

Figure 1. Cocooning the ice-cube with leaves

In particular, the findings pointed to the ability of the children to generate basic argumentation to express their thinking about thermal insulation and provide an explanation about the phenomenon. The qualitative data analysis has shown that all the children (6/6) were able to provide an argument about the need for insulating the ice-cube to prevent melting. The following excerpt (Excerpt 1) illustrates indicative examples of children's argumentation for insulating the ice-cubes.

\section{Excerpt 1: Children's arguments around insulating ice to prevent melting}

Early childhood teacher (E): Hedgehog, what would you do? Would you wrap the snowball?

Hedgehog 1 (H1): I would wrap it.

E: Aaa, why?

H1: In order not to, not to... lose.... lose the cold.

$[\ldots]$

E: Yes. And if we don't have leaves, will we wrap it or leave it like that?

H1: We will leave it like that.

E: What will happen if we leave it like that?

H1: It will melt.

[...]

Rabbit 1 (R1): With plastic.

E: Ah, with the plastic. Have you seen at your home wrapping cold things in plastic?

R1: We've seen ice wrap. 
E: Why do you think this is happening? Does mom do it at home?

R1: [affirmative nod]

E: Do you know why she does this?

R1: Why?

E: Do you know?

R1: In order not to melt the ice-cubes.

$[\ldots]$

E: Do you agree with your friend who chose to wrap it in foil?

H1: Yes.

E: So, you would wrap it with the same material?

H1: Yes.

E: Why?

H1: To keep it a little cold.

E: Have you seen something like this somewhere and thought about it? How did you think of that?

H1: Yes, my mom, when we don't have a bag to put it in, she puts it in aluminum foil so that they don't leave it, and then she keeps it that way.

The above excerpt illustrates how being in the role of the hedgehog or the rabbit and trying to provide a solution to the problem that emerged from the story children begun crafting a narrative around the science concept. This science narrative included arguments that are suggestive of the realization of cause and effect relations between elements related to the phenomenon such as that wrapping results to keep the cold (insulation) and not wrapping results to lose the cold (melting). What is also important here is that children used their everyday experiences to craft the science narrative and support their arguments.

Drawings were also used as a supplementary means for the children to express as well as document their thinking about thermal insulation. In the indicative drawings presented below (Figures 2 and 3) children drew the element that they consider as critical for the thermal insulation of the snowball, which is the leaves. In particular, at one drawing (Figure 3) one child also decided to draw an acorn in the snowball expanding the narrative about how snow is going to keep the acorn also fresh.

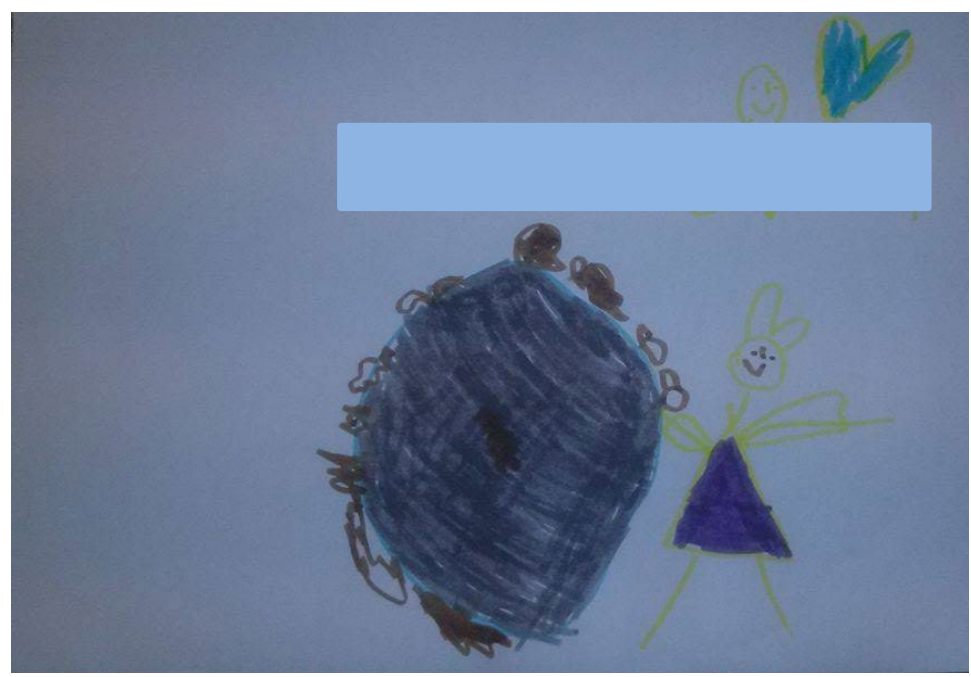

Figure 2. Drawing the rabbit cocooning the snowball with leaves 


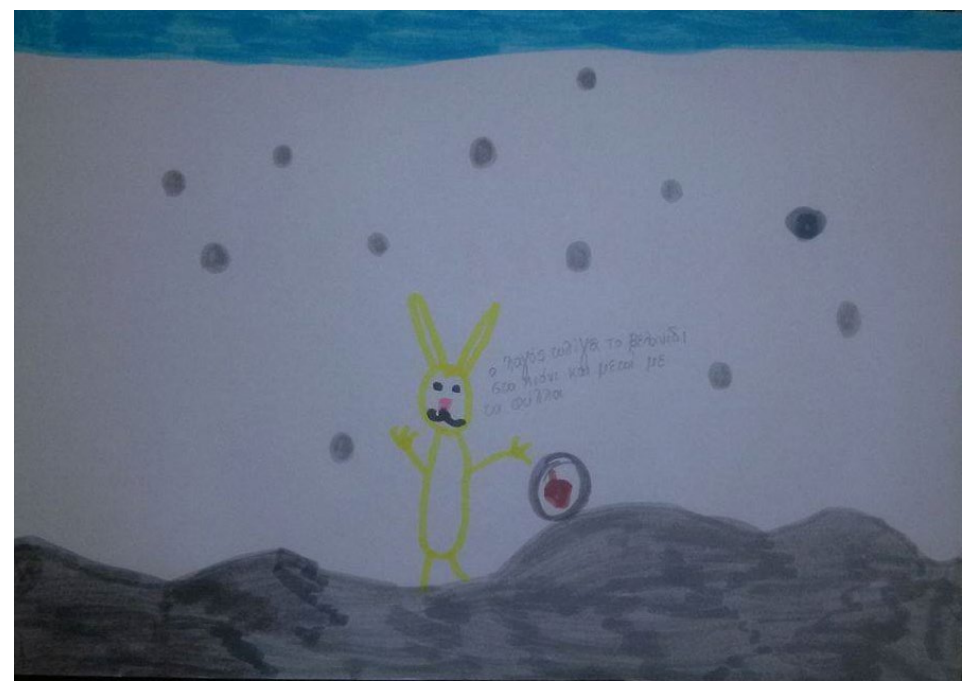

Figure 3. Drawing the rabbit cocooning an acorn with snow and leaves

\section{Relating the Phenomenon with the Thermal Condition and Changes in Temperature}

Four out of six (4/6) children were able to develop a basic explanation about the concept of thermal insulation relating the phenomenon with the thermal condition and changes in temperature (e.g., "It will not melt because it will be cold", "it will melt because spring will come", "it will melt because when spring comes everything melts because it is too hot", "it will melt because it is too hot"). This understanding is particularly important for approaching thermal insulation in a way that is compatible with the scientific model that can be used in early childhood education about this concept. Indicative examples of children's explanations related to the thermal condition and changes in temperature are presented in the following excerpt (Excerpt 2).

Excerpt 2: Science narratives around relating the phenomenon with the thermal condition and changes in temperature

E: And if you don't wrap it with leaves, what will happen?

Rabbit 3 (R3): It will melt!

E: A! Why?

R3: [laughs] Why? Because when spring comes, everything melts!

E: A! Why is that?

R3: Why? Because it's too hot!

$[\ldots]$

E: Would it melt? While if we wrap it with aluminium foil, what will happen?

Hedgehog 2 (H2): It wouldn't melt.

E: Why?

H2: Why (...) because the sun can't burn the foil.

This excerpt illustrates how children expand their science narratives about insulation during their dramatic play. What is important here is that as the dramatic play evolves children reach and express more advanced understandings of insulation. It appears to be able to connect the phenomenon to thermal conditions and changes in temperature. This is a core idea in understanding thermal insulation.

Identifying Materials and Objects Based on The Criterion of Insulating Property and Distinguishing These Materials and Objects from Others with Non-Insulating Properties

During their dramatic play, children had the opportunity to choose from a wide range of materials and objects such as fabric, aluminium foil, plastic bag, a paper napkin to insulate the ice-cubes (see Figure 
$4)$.

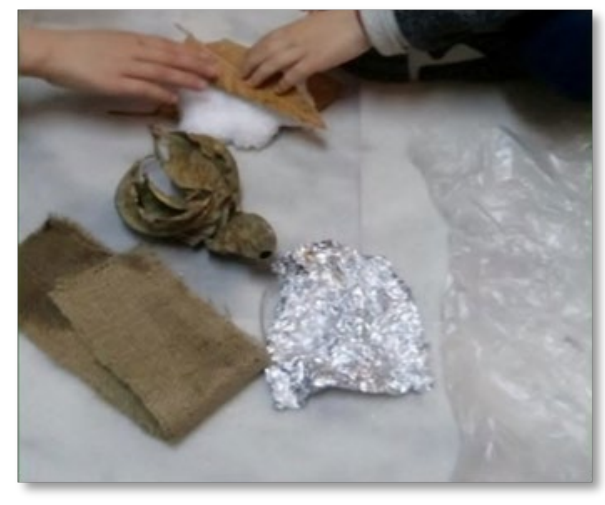

Figure 4. Children select materials and objects to cocoon the ice-cube

The findings revealed that the children were able, to some extent, to approach the insulating or noninsulating property of the materials. This is evident from the fact that most of the children (4/6) selected aluminium foil as the most suitable for maintaining the "frozen snowball". Respectively, most of the children (5/6) considered the fabric inappropriate as a material for the preservation of the "frozen snowball". Each child developed their reasoning to justify his/her choice, whether it was about snowball management or the choice of material or object. Paper was not selected as an appropriate material from most of the children (5/6). Regarding the choice of paper as a suitable material, only one child chose it without giving a justification.

Excerpt 3. Using the criterion of insulating property and distinguishing materials and objects based on this criterion

E: Would you wrap it with something? Or would you leave as it is?

(R1): I would wrap it with...

E: Yes.

R1: (holds the aluminium foil)

E: With that?

R1: [affirmative nod]

E: Do you know what that is?

R1: Aluminium foil.

E: Ah! And why would you wrap it with this and not with the rest?

R1: In order not to melt...

$[\ldots]$

E: If you wrap the snowball with this fabric, what will happen?

R1: I think it will melt.

$[\ldots]$

E: Are you thinking of something else that we could wrap around so it wouldn't melt? Something you've ever seen at home.

R1: With plastic.

E: Ah with the plastic. Have you seen your home wrap cold things in plastic?

R1: We've seen ice wrap.

$[\ldots]$

E: Would you choose the napkin?

Hedgehog 2 (H2): No. 
E: Why?

H2: Because it would melt.

E: It would melt. While with what you chose, what will happen?

H2: It wouldn't melt.

$[\ldots]$

E: So, what materials did you choose?

Rabbit 3 (R3): Aluminium foil and a bag.

E: And if you don't wrap the snowball with something, what will happen?

R3: It will melt. Look at the water (means the water from the ice melting)!

E: How do you know?

R3: Because look at the water! The school is full of!

E: But what if we wrapped the snowball with this fabric?

R3: It will melt again!

E: Why do you say it will melt again?

R3: Why? (shakes hands as a sign of wonder). See for yourself why. Look, what does it look like!

E: What does it look like?

R3: Water!

The above excerpt demonstrates that children were aware of the fact that different qualities and types of materials and objects can lead to diverse results regarding thermal insulation. The dialogues highlight that this realization allowed children to distinguish materials and objects as efficient and nonefficient options in insulating the ice-cubes during their dramatic play. What is also important here is that, while playing, children develop a trial skill to test the efficiency of the materials (e.g., E: How do you know? R3: Because look at the water! The school is full of!).

\section{Realizing That the Use of Amplified Insulation Materials Can Lead to Better Insulation Results}

While being in dramatic play as the characters of the story and handling the provided objects and materials, children also appeared to be able to realize that the use of more amplified insulation materials can lead to better insulation results. Regarding the choice of a plastic bag as a suitable material, one child chose it as the main material, emphasizing the quantity of the bags that should be used. That is, he considered plastic bags to be suitable for wrapping snowballs, provided they were "many". For example, "I know why if we wrap one, one, one, one, once it gets there it won't melt".

Excerpt 4. Realising that amplified insulation materials can lead to better insulation results

E: Or would you choose something else?

R3: More bags! Not just one!

E: Ah! Why?

R3: Why? In order not to melt!

E: Have you seen this somewhere? How do you know?

R3: I know this because if we wrap one, one, one, one, once it gets up there and it is no way it will melt!

E: With bags! So, in other words, you say that we have to wrap it, but with many, many, many bags.

R3: Yes.

E: Is one not enough?

R3: (...) No.

The excerpt presented here showcases that through their extensive engagement with the concept during dramatic play children were able to gradually deepen their understanding of diverse aspects of 
thermal insulation. The argumentation in the above excerpt is suggestive that the child realized that amplified insulation solutions can lead to better insulation results. What lies behind this realization is the advanced understanding that layers of insulation can block thermal transfer.

\section{Conclusions and Discussion}

The present study explored how dramatic play created the conditions for tracing and supporting the process of thermal insulation concept formation in early childhood settings. Evidence showed that through dramatic play inspired by a children's book, preschool children were able to conceptualize thermal insulation and develop explanations about the phenomenon. What was also found is that following the flow of children's dramatic play early childhood teachers managed to pose questions and better unpack children's thinking and stimulated them to wonder more thoroughly and develop their understandings about thermal insulation within play-based settings.

In particular, the qualitative analysis of the empirical data showed that dramatic play allowed children to a) develop basic argumentation to express their thinking about the phenomenon realizing that several materials and objects can prevent ice melting; $b$ ) relate the phenomenon with the thermal condition and changes in temperature; c) identify materials and objects with insulating properties and distinguish these materials and objects from others with non-insulating properties, and d) come to the conclusion that the use of amplified insulation materials can lead to better insulation results. The overall analysis also highlighted that dramatic play created the conditions for the children to make conceptual bridges between their everyday knowledge and experience about thermal insulation and a scientific understanding of the concept. Almost all children (5/6) reported experiences from their daily lives such as domestic routines, housekeeping, cartoons, free play with toys, objects and materials, during the interaction process with their friends and early childhood teachers. One child initially reported seeing his mom at home wrapping "ice" in plastic to keep it from melting. His peer, listening to his friend, agreed that his mom does the same and even added that when she does not have bags, she wraps them in aluminum foil. Another child reported something related to the general issue, stating that he knew that the snow would melt at some point because it had snowed in his apartment building. This is not directly related to the choice of material but suggests an appropriate correlation of the child with the subject. What was also important is that children used the book several times during their dramatic play to get more information from the illustrated pictures regarding the materials and the procedure of thermal insulating the snowball. This is suggestive that children were motivated through dramatic play to approach thermal insulation as a real-life phenomenon and as a real-life problem that has to be solved. The dramatic framework reinforced children's engagement with the collective science experience. At the same time, it allowed early childhood teachers to follow and process children's narratives and actions in a more naturalistic way than interviewing children.

The present study adds to the literature in a twofold way. Firstly, the findings provide important insights into a science concept that has not been previously explored systematically in the literature of early childhood science education research. This is particularly important given the fact that young children experience thermal insulation as an everyday phenomenon in their daily life. A better understanding of how young children think and wonder about thermal insulation can orient and shape teaching and learning interventions in early childhood settings. Interventions tailored made to young children's conceptual interests and needs can support children to form explanatory models about thermal insulation that are compatible with the models used in early childhood education.

Secondly, the study provides an alternative to the traditional tracing procedures of children's ideas, mental representations, and pre-conceptions. The study demonstrates empirical evidence of how dramatic play can be used for tracing as well as supporting young children's ideas and thinking in science. Thus, the evidence allows us to rethink tracing procedures in early childhood science education as social and cultural activities incorporated into the child's everyday educational reality. This realisation informs everyday practice providing a pedagogical framework that supports early childhood teachers to promote young children's engagement with the natural and technical world through play-based settings and in a way that 
is meaningful and enjoyable for the children.

The study concludes by highlighting the need for conducting further research on children's ideas about thermal insulation. Future research on this theme can consider the expansion of the number of participants as well as the design of a precursor model that illustrates the challenges as well as the opportunities and the possibilities young children have while approaching thermal insulation in early childhood settings. What is also important to be considered in future research is the need for designing and implementing playful and meaningful for the child procedures for tracing and detecting young children's ideas, representations, and pre-conceptions in science.

\section{Declarations}

Acknowledgements: Not applicable.

Authors' contributions: GF: 25\%, AA: 25\%, SZ: 25\%, KR: 25\%.

Competing interests: The authors declare that they have no competing interests.

Funding: Not applicable.

\section{References}

Bar, V. (1989). Children's views about the water cycle. Science Education, 73(4), 481- 500. https://doi.org/10.1002/sce.3730730409

Bar, V., \& Galili, I. (1994). Stages of children's views about evaporation. International Journal of Science Education, 16(2), 157-174. https://doi.org/10.1080/0950069940160205

Bodrova, E., \& Leong, D. J. (1998). Development of dramatic play in young children and its effects on self-regulation: The Vygotskian Approach. Journal of early childhood teacher education, 19(2), 115-124. https://doi.org/10.1080/0163638980190204

Brown, V. (2017). Drama as a valuable learning medium in early childhood. Arts Education Policy Review, 118(3), 164-171. https://doi.org/10.1080/10632913.2016.1244780

Cain, R., \& Lee, V. R. (2020). A Thermometer for Kindergarten data inquiry. In B. Tangney, J. R. Byrne \& C. Girvan (Eds), Proceedings of the 2020 Constructionism Conference (pp. 63-65). Dublin, Ireland.

Calo Mosquera, N., García-Rodeja Gayoso, I., \& Sesto Varela, V. (2021). Construyendo conceptos sobre electricidad en infantil mediante actividades de indagación. Enseñanza de las Ciencias, 39(2), 223-240. https://doi.org/10.5565/rev/ensciencias.3238

Christidou, V., Kazela, K., Kakana, D., \& Valakosta, M. (2009). Teaching magnetic attraction to preschool children: A comparison of different approaches. International Journal of Learning, 16(2), 115-128. https://doi.org/10.18848/1447-9494/CGP/v16i02/46130

Convertini, J. (2019). Contributo allo studio dei tipi di argomento in situazioni di problem solving tecnico da parte di bambini in età prescolare. [Unpublished doctoral dissertation]. Université de Neuchâtel.

Courtney, R. (1989). Play, drama \& thought: The intellectual background to dramatic education. Dundurn.

Cruz-Guzmán, M., García-Carmona, A., \& Criado, A. M. (2017). Aprendiendo sobre los cambios de estado en educación infantil mediante secuencias de pregunta-predicción- comprobación experimental. Enseñanza de las Ciencias, 35(3), 175-193.

Delserieys, A., Impedovo, M. A., Fragkiadaki, G., \& Kampeza, M. (2017). Using drawings to explore preschool children's ideas about shadow formation. Review of Science, Mathematics and ICT Education, 11(1), 55-69.

Dorion, K. (2009). Science through Drama: A multiple case exploration of the characteristics of drama activities used in secondary science lessons. International Journal of Science Education, 31(16), 2247-2270. https://doi.org/10.1080/09500690802712699

Dunn, J. (2003). Linking drama education and dramatic play in the early childhood years. In S. Wright (Ed.), Children, meaning-making and the arts. Pearson Education Australia.

Elkonin, D. (1977). Toward the problem of stages in the mental development of the child. In M. Cole (Ed.), Soviet developmental psychology. M. E. Sharpe.

Elkonin, D. (1978). Psikhologija igry [The psychology of play]. Pedagogika.

Fleer, M. (2008). Understanding the dialectical relations between everyday concepts and scientific concepts within Play-Based Programs. Research in Science Education, 39(2), 281-306. https://doi.org/10.1007/s11165-008-9085-x

Fleer, M. (2011). 'Conceptual Play': foregrounding imagination and cognition during concept formation in early years education. Contemporary Issues in Early Childhood, 12(3), 224-240. https://doi.org/10.2304/ciec.2011.12.3.224 
Dramatic play as a means to explore and support preschool children's...

Fleer, M. (2013). Affective imagination in science education: Determining the emotional nature of scientific and technological learning of young children. Research in Science Education, 43(5), 2085-2106. https://doi.org/10.1007/s11165-012-9344-8

Fleer, M. (2018). Conceptual Playworlds: The role of imagination in play and learning. Early Years, 1-12. https://doi.org/10.1080/09575146.2018.1549024

Fleer, M., Fragkiadaki, G., \& Rai, P. (2020). STEM begins in infancy: Conceptual PlayWorlds to support new practices for professionals and families. International Journal of Birth and Parent Education, 7(4), 27-31.

Fragkiadaki, G., \& Ravanis, K. (2015). Preschool children's mental representations of clouds. Journal of Baltic Science Education, 14(2), 267-274.

Furman, L. (2000). In support of drama in early childhood education, again. Early Childhood Education Journal, 27(3), 173-178. https://doi.org/10.1007/BF02694231

Gao, Q., \& Hall, A. H. (2019). Supporting preschool children's learning through dramatic play. Teaching Artist Journal, 17(3-4), 103105. https://doi.org/10.1080/15411796.2019.1680236

Hadzigeorgiou, Y. (2002). A study of the development of the concept of mechanical stability in preschool children. Research in Science Education, 32(3), 373-391. https://doi.org/10.1023/A:1020801426075

Kada, V., \& Ravanis, K. (2016). Creating a simple electric circuit with children between the ages of five and six. South African Journal of Education, 36(2), 1-9. https://doi.org/10.15700/saje.v36n2a1233

Kalogiannakis, M., Nirgianaki, G. M., \& Papadakis, S. (2018). Teaching magnetism to preschool children: the effectiveness of picture story reading. Early Childhood Education Journal, 46(5), 535-546. https://doi.org/10.1007/s10643-017-0884-4

Kambouri, M., \& Michaelides, A. (2014). Using drama techniques for the teaching of early years science: A case study. Journal of Emergent Science, 7, 7-14.

Kambouri-Danos, M., Ravanis, K., Jameau, A., \& Boilevin, J. M. (2019). The water state changes in 5-6 years old children's thinking: The construction of a precursor model. Early Childhood Education Journal, 47(4), 475-488. https://doi.org/10.1007/s10643-019$\underline{00937-5}$

Kampeza, M., Vellopoulou, A, Fragkiadaki, G., \& Ravanis, K. (2016). The expansion thermometer in preschoolers' thinking. Journal of Baltic Science Education, 15(2), 185-193.

Larsson, J. (2013) Children's encounters with friction as understood as a phenomenon of emerging science and as "opportunities for learning. Journal of Research in Childhood Education, 27(3), 377-392. https://doi.org/10.1080/02568543.2013.796335

Leont'ev, A. N. (1978). Activity, consciousness, and personality. Prentice-Hall.

Malleus, E., Kikas, E., \& Marken, T. (2017). Kindergarten and primary school children's everyday, synthetic, and scientific concepts of clouds and rainfall. Research in Science Education, 47(3), 539-558. https://doi.org/10.1007/s11165-016-9516-Z

McGregor, D. (2012). Dramatising Science Learning: Findings from a pilot study to re-invigorate elementary science pedagogy for five- to seven-year olds. International Journal of Science Education, 34(8), 1145-1165. https://doi.org/10.1080/09500693.2012.660751

Mellou, E. (1994). The values of dramatic play in children. Early Child Development and Care, 104(1), 105-114. https://doi.org/10.1080/0300443941040109

Metcalfe, J. A. R., Abbott, S., Bray, P., Exley, J., \& Wisnia, D. (1984). Teaching science through drama: An empirical investigation. Research in Science \& Technological Education, 2(1), 77-81. https://doi.org/10.1080/0263514840020109

Neelands, J. (2002). Making sense of drama: A guide to classroom practice. Heinemann Educational.

Ødegaard, M. (2003). Dramatic Science. A critical review of drama in Science Education. Studies in Science Education, 39(1), 75-101. https://doi.org/10.1080/03057260308560196

Paik, S. H., Cho, B. K., \& Go, Y. M. (2007). Korean 4- to 11-year-old student conceptions of heat and temperature. Journal of Research in Science Teaching: The Official Journal of the National Association for Research in Science Teaching, 44(2), $284-302$. https://doi.org/10.1002/tea.20174

Pantidos, P., Herakleioti, E., \& Chachlioutaki, M.-E. (2017). Reanalysing children's responses on shadow formation: A comparative approach to bodily expressions and verbal discourse. International Journal of Science Education, 39(18), 2508-2527. https://doi.org/10.1080/09500693.2017.1392644

Pantidos, P., Spathi, K., \& Vitoratos, E. (2001). The use of drama in science education: The case of "Blegdamsvej Faust". Science $\mathcal{E}$ Education, 10(1), 107-117. https://doi.org/10.1023/A:1008769401292

Pea, R. D. (1993). Learning scientific concepts through material and social activities: Conversational analysis meets conceptual change. Educational Psychologist, 28(3), 265-277. https://doi.org/10.1207/s15326985ep2803_6 
Glykeria FRAGKIADAKI et al.

Rai, R., Fleer, M., \& Fragkiadaki, G. (2021). Theorising digital tools: Mutual constitution of the person and digital in a Conceptual PlayWorld. Human Arenas, 1-18. https://doi.org/10.1007/s42087-020-00178-8

Ravanis, K. (2014). Les représentations des enfants de 5-6 ans sur la fusion et la solidification du sel, comme support pour le déploiement des activités didactiques. International Journal of Research in Education Methodology, 6(3), 943-947.

Ravanis, K. (2017). Early Childhood Science Education: State of the art and perspectives. Journal of Baltic Science Education, 16(3), 284288. https://doi.org/10.24297/ijrem.v6i3.3867

Ravanis, K., \& Bagakis, G. (1998). Science Education in Kindergarten: Sociocognitive perspective. International Journal of Early Years Education, 6(3), 315-327. https://doi.org/10.1080/0966976980060306

Ravanis, K., Kaliampos, G., \& Pantidos, P. (2021). Preschool children science mental representations: The sound in space. Education Sciences, 11(5), 242-259. https://doi.org/10.3390/educsci11050242

Remountaki, E. L., Fragkiadaki, G., \& Ravanis, K. (2017). The approach of solid in liquid dissolution in early childhood education settings: A socio-cultural approach. European Journal of Education Studies, 3(6), 303-318.

Rodríguez-Moreno, J., Pro-Chereguini, C., \& Pro-Bueno, A. (2020) Qué se puede aprender «Jugando con la electricidad» en Educacion Infantil?. Revista Eureka sobre Ensepanza y Divulgacion de las Ciencias, 17(2), 2202. https://doi.org/10.25267/Rev_Eureka_ensen_divulg_cienc.2020.v17.i2.2203

Russell, T., Harlen, W., \& Watt, D. (1989). Children's ideas about evaporation. International Journal of Science Education, 11(5), $566-576$. https://doi.org/10.1080/0950069890110508

Saçkes, M., Smith, M. M., \& Trundle, K. C. (2016). U.S. and Turkish preschoolers' observational knowledge of astronomy. International Journal of Science Education, 38(1), 116-129. https://doi.org/10.1080/09500693.2015.1132858

Sacks, H. (1995). Lectures on conversation. Blackwell. https://doi.org/10.1002/9781444328301

Smith, M. M., \& Trundle, K. C. (2014). Shrieks and shrills: Investigating sound in preschool. Science and Children, 52(4), 38-43.

Solomonidou, C., \& Kakana, D. M. (2000). Preschool children's conceptions about the electric current and the functioning of electric appliances. European Early Childhood Education Research Journal, 8(1), 95-111. https://doi.org/10.1080/13502930085208511

Trundle, K. C., \& Saçkes, M. (2010). Look! It is going to rain: Using books and observations to promote young children's understanding of clouds. Science and Children, 47(8), 29-31.

Tytler, R. (2000). A comparison of year 1 and year 6 students' conceptions of evaporation and condensation: Dimensions of conceptual progression. International Journal of Science Education, 22(5), 447-467. https://doi.org/10.1080/095006900289723

Varelas, M., Pappas, C. C., Tucker-Raymond, E., Kane, J., Hankes, J., Ortiz, I., \& Keblawe-Shamah, N. (2010). Drama activities as ideational resources for primary-grade children in urban science classrooms. Journal of Research in Science Teaching, 47(3), 302325. https://doi.org/10.1002/tea.20336

Vidal Carulla, C., Christodoulakis, N., \& Adbo, K. (2021). Development of preschool children's executive functions throughout a playbased learning approach that embeds science concepts. International Journal of Environmental Research and Public Health, 18(2), 588. https://doi.org/10.3390/ijerph18020588

Vygotsky, L. S. (1987). The collected work of L. S. Vygotsky: Vol. 1. Problems of general psychology. Plenum Press.

Wolf, D. P., \& Kase-Polisini, J. (1985). Dramatic imaginations. Creative drama in a developmental context. University Press of America.

Wright, P. (1999). The thought of doing drama scares me to death. Research in Drama Education, 4(2), $227-237$. https://doi.org/10.1080/1356978990040206 